\title{
Construção de práticas de letramento digital na formação inicial do professor de lingua materna
}

Construction of digital literacy practices

in the pre-service native language teacher

\author{
Wagner Rodrigues Silva ${ }^{1}$ \\ Naiane Vieira dos Reis ${ }^{2}$
}

\begin{abstract}
Resumo
Neste estudo, processo de letramento digital de professores em formação inicial é tomado como objeto de investigação. Na perspectiva interdisciplinar da Linguística Aplicada, este trabalho toma como ponto de partida contribuições dos novos estudos do letramento, focalizando principalmente a apropriação do digital em ambientes de ensino, além de considerar algumas discussões sobre os saberes profissionais, no sentido de investigar como se desenvolvem os saberes docentes a respeito do letramento digital no estágio supervisionado obrigatório de uma licenciatura. A problematização de práticas e recursos pedagógicos na formação inicial de professores contribui para uma formação mais crítica e reflexiva sobre o uso das Tecnologias de Informação e Comunicação (TIC) no ensino. O ambiente acadêmico precisa problematizar algumas discussões sobre aspectos do ensino que são emergentes nas práticas educativas, tendo em vista uma postura crítica dos futuros professores diante dos desafios pedagógicos instaurados.
\end{abstract}

Palavras-chave: Formação de professores. Pesquisa interventiva. Saberes profissionais.

\begin{abstract}
In this paper, the process of digital literacy of pre-service teachers is taken as object of research. In interdisciplinary perspective of Applied Linguistics, this work takes as its starting point contributions from the new literacy studies, focusing primarily on digital appropriation in educational settings. It considers some discussions on the professional knowledge, to investigate how the teacher knowledge about digital literacy is developed in a supervised compulsory pre-service teacher training. The questioning of practices and teaching resources in pre-service teacher education contributes to a more critical and reflective training on the use of Information and Communication

\footnotetext{
${ }^{1}$ Doutor em Linguística Aplicada, professor associado da Universidade Federal do Tocantins (UFT) e bolsista produtividade do CNPq. E-mail: wagnerodriguesilva@gmail.com.

2 Doutoranda em Letras: Ensino de Língua e Literatura, na Universidade Federal do Tocantins (UFT) e bolsista de doutorado da Coordenação de Aperfeiçoamento de Pessoal de Nivel Superior (CAPES). E-mail: naianevieira@hotmail.com.
} 
Technologies (ICT) in teaching. The academic environment needs to discuss some aspects of education that are emerging in the educational practices, with a view to a critical attitude of future teachers brought before the pedagogical challenges.

Keywords: Teacher education. Interventional research. Professional knowledges.

\section{Introdução}

Neste artigo, apresentamos resultados de uma investigação científica a respeito da construção de práticas de letramento digital na formação de professores, mais precisamente nas disciplinas de estágio supervisionado obrigatório, componentes curriculares das licenciaturas, denominação utilizada no Brasil para nomear os cursos superiores de formação inicial de professores. Os resultados produzidos contribuem para as investigações desenvolvidas no grupo de pesquisa "Práticas de linguagens" - PLES (CNPq/UFT). Focalizamos práticas de uso da escrita e, em especial, as de reflexão pela/sobre a escrita envolvendo ambientes digitais de interação pela linguagem, mobilizados em contextos de instrução do ensino básico e da formação inicial de professores nas licenciaturas.

$\mathrm{Na}$ investigação realizada, a articulação entre o ensino básico e o superior é desencadeada pela própria natureza dos estágios supervisionados obrigatórios, momento em que os professores em formação inicial - aqui denominados de alunos-mestre - observam e ministram aulas em escolas de ensino básico, sob a supervisão do professor-formador, responsável pelas disciplinas de estágio obrigatório na universidade. A carga horária dessas disciplinas é distribuída em aulas presenciais e atividades práticas. Nas primeiras, são trabalhados, na universidade, conteúdos disciplinares relevantes para as atividades práticas a serem desenvolvidas. Nas segundas, são planejadas aulas e preparados materiais didáticos, ainda na universidade, e, posteriormente, ministradas aulas de disciplinas escolares específicas, na própria escola de ensino básico.

Apresentamos uma análise descritiva de alguns modos de reflexão pela escrita, realizados por alunos-mestre, sobre usos de ferramentas digitais 
como recursos pedagógicos na disciplina escolar de Língua Portuguesa, no contexto da escola pública brasileira de ensino básico. A análise se configura como continuidade das investigações realizadas sobre as implicações da escrita reflexiva, mediada pelo gênero relatório de estágio supervisionado, produzido em licenciaturas diversas, para o fortalecimento do letramento do professor em formação inicial (SILVA, 2012; 2013; SILVA; DINIZ, 2014; MELO, 2015).

Três relatórios escritos por uma mesma dupla de alunos-mestre são tomados como principais documentos investigados nesta pesquisa. As atividades em dupla são bastante comuns durante os estágios supervisionados obrigatórios. Interessa-nos investigar mais diretamente as formas de apropriação pelos alunos-mestre de saberes acadêmicos sobre os usos das Tecnologias da Informação e Comunicação (TIC) no contexto escolar. Tais formas são registradas na escrita acadêmica dos relatórios, os quais são produzidos como trabalho avaliativo final dos estágios. Ou seja, na materialidade textual dos relatórios estão semiotizadas práticas sociais características do contexto de produção e circulação desse gênero textual.

Ao analisarmos a materialidade textual dos relatórios, focalizamos as reflexões escritas sobre práticas inovadoras do ensino de Língua Portuguesa, uma vez que, usualmente, as tecnologias digitais são mobilizadas como artefatos responsáveis pela inovação desejada no trabalho docente. Por um lado, as práticas de ensino são inovadoras quando conseguem romper com atividades didáticas caducantes, as quais são pouco produtivas para responder as desafiadoras demandas para a formação discente na contemporaneidade. Por outro lado, a inovação não se caracteriza, necessariamente, pela transformação revolucionária de práticas pedagógicas corriqueiras, conforme sentido atribuído a tais palavras no senso comum. Nessa perspectiva, assumimos a acepção de inovação proposta por Signorini (2007), ao tematizar mudanças no ensino e na formação do professor de língua. A autora compreende inovação 
como deslocamento ou reconfiguração dos modos rotineiros de raciocinar/agir/avaliar em questões de estudos e de ensino da língua, reconfiguração essa impulsionada por demandas institucionais. [...] uma categoria de base interpretativa, portanto não-universal e muito menos transparente ou neutra: inovador é sempre uma qualificação positiva que favorece determinados agentes sociais em detrimento de outros, o que faz com que esteja sempre sujeita a contestação (SIGNORINI, 2007, p. 9).

Este artigo está organizado em três seções principais, além desta Introdução, Considerações finais e Referências. Em Contexto de geração dos dados, descrevemos o espaço social complexo em que estão situadas as disciplinas de estágio supervisionado, destacando relações estabelecidas entre atividades acadêmicas e escolares instauradas nas referidas disciplinas. Em Letramentos na formação do professor, apresentamos uma releitura de alguns conceitos desenvolvidos nos estudos do letramento a partir de demandas existentes para o uso de tecnologias digitais no contexto de formação inicial de professores. Em Resultados produzidos, apresentamos alguns resultados da análise realizada de produções escritas dos alunosmestre. Tais resultados estão organizados em três subseções, Relatório I Reflexões sobre observação de aulas, Relatório II - Reflexões sobre regência de aulas, Relatório III - Reflexões sobre regência de aulas, as quais correspondem às disciplinas de estágio supervisionado focalizadas nesta investigação.

\section{Contexto de geração dos dados}

Os dados analisados foram gerados na Licenciatura em Letras (Habilitações em Língua Portuguesa e Língua Inglesa), ofertada no Campus Universitário de Araguaína, pertencente à Universidade Federal do Tocantins (UFT). Na matriz curricular do curso, não há disciplinas em que os estudos do letramento - incluindo aí os referentes ao digital - sejam considerados como conteúdo programado, ainda que seja demandado dos professores egressos da licenciatura o trabalho didático com práticas de letramento 
digital no ensino básico (RIBEIRO; COSCARELLI, 2010) ${ }^{3}$. Considerando que as demandas mais imediatas do ensino básico chegam à universidade pelos estágios supervisionados obrigatórios das licenciaturas, os formadores responsáveis por tais disciplinas usufruem de maior autonomia para inserir novos conteúdos a serem trabalhados nos estágios.

As aulas do estágio supervisionado são concebidas como um espaço social complexo, informado pela ação de atores de diferente natureza humanos e não humanos (SILVA, 2011; 2013), os quais trazem na própria materialidade corporal práticas de outros contextos culturais. No estágio, são conjugadas, por exemplo, formação acadêmica, experiência no ensino básico, uso de material didático. Essa fusão de práticas contribui para a formação inicial do professor, não se restringindo apenas às teorias acadêmicas ou saberes disciplinares trabalhados na universidade. Qualquer investigação científica situada no contexto do estágio supervisionado da licenciatura requer articulação com outros contextos que informam o trabalho didático desenvolvido na disciplina, caso contrário a investigação produzirá resultados simplificados para responder às demandas da formação do professor (GIBSON, 2003; SILVA, 2012).

Na Figura 1 sintetizamos o espaço social complexo em que estão inseridas as atividades teóricas e práticas do estágio supervisionado, requerendo das investigações científicas sobre o assunto, conforme discutido em Silva (2012, p. 27), uma abordagem "[...] minimamente interdisciplinar, em resposta às demandas próprias da referida disciplina".

\footnotetext{
${ }^{3}$ No novo Projeto Pedagógico do Curso (PPC), que entrou em vigor em Agosto de 2010, a licenciatura em Letras conta com uma disciplina obrigatória que focaliza as tecnologias no ensino. Tal disciplina é denominada de "Educação e tecnologias contemporâneas", e tem por objetivo geral: "Refletir sobre diferentes aspectos que envolvem a inserção de novas tecnologias no universo do conhecimento e suas implicações para a educação". Os dados investigados neste artigo não foram gerados em turmas orientadas pelo novo PPC.
} 


\section{Figura 1 - Aulas de Estágio como Espaço Complexo}

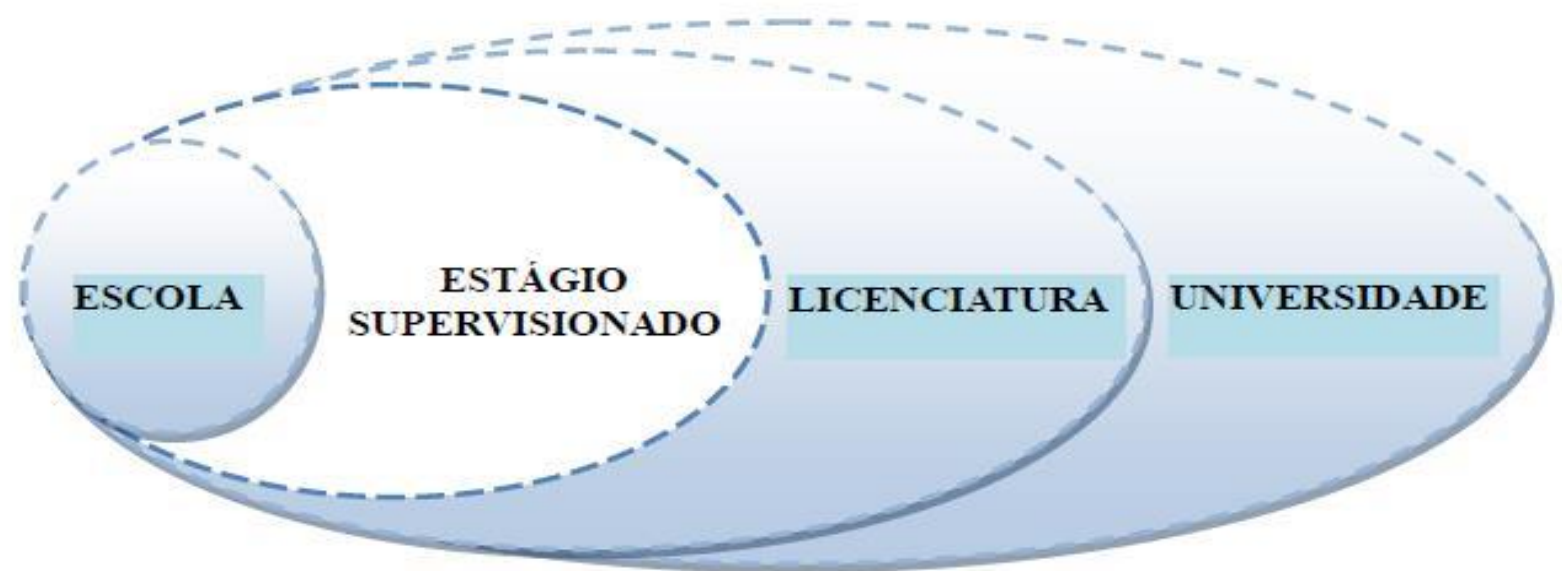

Retomando a discussão do contexto de formação aqui focalizado, a universidade possui apenas 13 anos de serviços prestados à comunidade. É marcada por tensões características de instituições recém-criadas, tendo como aspecto agravante a origem do processo de federalização de uma universidade estadual. A UFT procura assumir a meritocracia a partir da formação do próprio quadro de servidores com profissionais qualificados, opondo-se a práticas de clientelismo e de favorecimento dos pares, características da antiga instituição. Nesse contexto está inserida a Licenciatura em Letras, num campus com outros seis cursos de formação de professores, além de bacharelados e tecnólogos. Mesmo vinculada a um programa de pós-graduação que vem se fortalecendo bastante nos últimos anos, a Licenciatura em Letras é orientada por uma matriz curricular bastante presa à tradição de formação do professor, com disciplinas clássicas na área, as quais privilegiam os estudos linguísticos e, praticamente, ignoram possiveis contribuições originárias das pesquisas desenvolvidas na Linguística Aplicada ${ }^{4}$ (SILVA et al., 2017).

Usufruindo da autonomia possuída pelos formadores de professores, realizamos uma intervenção pedagógica numa turma do $7^{\circ}$ período da Licenciatura em Letras, na disciplina do terceiro estágio supervisionado em ensino de Língua Portuguesa. O objetivo da intervenção foi instigar

\footnotetext{
${ }^{4}$ Referimo-nos aqui ao Programa de Pós-Graduação em Letras: Ensino de Língua e Literatura, com cursos de mestrado, acadêmico e profissional, e doutorado.
} 
discussões teóricas e práticas pedagógicas que privilegiassem o letramento digital nas atividades realizadas na universidade e nas escolas de ensino básico, permitindo, portanto, uma maior familiarização dos formadores e alunos-mestre com o novo conteúdo trabalhado. Neste trabalho, a intervenção é focalizada indiretamente, uma vez que apenas alguns documentos aqui analisados foram produzidos pelos alunos-mestre durante o contexto mencionado.

Os resultados de pesquisa apresentados foram produzidos a partir de três relatórios escritos: um referente à prática de observação e dois à de observação e regência de aulas no Ensino Fundamental. Tais relatórios correspondem aos trabalhos finais das disciplinas Investigação da Prática Pedagógica e Estágio Supervisionado em Lingua Portuguesa: Língua e Literatura I, II e III. Os textos selecionados foram entregues como trabalho final das disciplinas por uma mesma dupla de alunos-mestre, os quais tematizam práticas de letramento digital nos relatos sobre as atividades realizadas na prática de observação e regência de aulas de Língua Portuguesa. O relatório produzido no terceiro estágio e os ensaios acadêmicos, focalizados na terceira seção deste artigo, foram produzidos no contexto mencionado de intervenção pedagógica.

A dupla selecionada pertence à turma em que realizamos a pesquisa interventiva. Envolveu-se nas propostas de atividade e nas leituras teóricas realizadas durante a intervenção. Muitos ficaram receosos e resistiram bastante à apropriação de saberes acadêmicos sobre os usos das TIC no contexto escolar. Considerando a individualidade das histórias de letramento desses alunos-mestre, alguns demonstraram pouca familiaridade com o uso de ambientes digitais em situações de ensino. Dessa forma, enquanto alguns procuravam se engajar no planejamento de situações de ensino, informadas por práticas de letramento digital, outros resistiam e preferiam ancorar as atividades realizadas exclusivamente na cultura do impresso.

Previamente, realizamos um levantamento de dados para diagnosticar a ocorrência de relatórios em que houve mobilização de saberes acadêmicos, 
envolvendo o letramento digital nas atividades do estágio supervisionado. $\mathrm{Na}$ pesquisa, também analisamos o modo como práticas de letramento digital são descritas nos relatórios. Para tanto, utilizamos o banco de dados do Centro Interdisciplinar de Memória dos Estágios Supervisionados das Licenciaturas (CIMES), localizado no campus universitário focalizado5. Dos 499 relatórios investigados da Licenciatura em Letras (habilitações em Lingua Portuguesa), produzidos entre os alunos de 2006 a 2011, encontramos apenas 12 relatórios com tematização das práticas aqui focalizadas. Todos os relatórios foram lidos e analisados sem mediação de ferramentas de busca. Nos documentos, não há um espaço privilegiado para a discussão das concepções ou efeitos do letramento digital no ensino básico. São recorrentes os argumentos dos alunos-mestre evidenciando o próprio esforço para despertar o interesse dos alunos e para ser mais dinâmico e inovador no planejamento e regência de aulas.

O relatório de estágio se configura como um espaço de reflexão sobre a prática pedagógica. Corresponde ao momento em que aluno-mestre também volta o olhar sobre o próprio trabalho pedagógico, avaliando a eficácia das atividades didáticas vivenciadas. Nesses documentos, é possível evidenciar concepções teóricas e práticas diversas sobre o ensino tematizado de língua materna, uma vez que as práticas sociais se materializam na escrita dos relatórios. A baixa ocorrência de relatórios que tematizam práticas de letramento digital pode evidenciar a ausência do conteúdo nas atividades teóricas dos estágios supervisionados obrigatórios ou, até mesmo, da matriz curricular da licenciatura6.

Os alunos-mestre demonstram incômodo com as práticas pedagógicas da tradição do ensino, ainda bastante evidentes em aulas observadas em

\footnotetext{
${ }^{5}$ O CIMES é um espaço de ensino, pesquisa e extensão, disponibilizado para a comunidade acadêmica se envolver em atividades de interesse dos estágios supervisionados obrigatórios das licenciaturas. O acervo do centro é composto principalmente por relatórios de estágio, além de outros materiais, como livros didáticos, relevantes para a formação inicial do professor.

6 Dentre as contribuições do uso de narrativas na formação inicial de professores, pontuadas por Gibson (2003, p. 37), destacamos que as narrativas funcionam como ferramentas de pesquisa, permitem a professores e alunos relatarem experiências, preocupações, anseios.
} 
escolas de ensino básico. Para as aulas de Língua Portuguesa, restam expectativas por alternativas para as práticas informadas exclusivamente por livros didáticos, tendo como conteúdos disciplinares a gramática normativa e a leitura sobre clássicos da literatura, mesmo que novos objetos de ensino, como a diversidade de gêneros textuais, ganhem espaço na sala de aula. Os alunos-mestre se dizem provocados pelo desinteresse dos alunos do ensino básico quanto às aulas assistidas, quando apenas a voz do professor é enunciada.

A tecnologia é apresentada pelos alunos-mestre como mecanismo desencadeador da inovação do ensino, pois seria responsável por despertar o interesse dos alunos pelas aulas de língua materna, conforme evidenciamos na seguinte passagem reproduzida de um relatório: "Com a proposta da utilização da internet e da criação do blog, propomo-nos a trabalhar um tema que fosse da realidade dos alunos, pois é notável o interesse dos alunos por esse tipo de abordagem" (Relatório II, 2011.2). O substantivo "interesse" caracteriza a prática avaliada como positiva pela dupla de estagiários.

Os relatórios de estágio são informados por saberes docentes diversos, mobilizados no fluxo aparentemente homogêneo, de dificil dissociação dos saberes. Para efeito didático, destacamos os disciplinares e os experienciais. Os primeiros podem ser caracterizados pelos aparatos teóricos que os alunos-mestre têm acesso durante sua formação inicial na licenciatura. Os segundos são aqueles adquiridos nas relações sociais, advindos de experiências adquiridas nas mais diversas situações de ensinoaprendizagem, envolvendo, inclusive, os saberes escolares, característicos das práticas pedagógicas por eles vivenciadas ainda no ensino básico. A leitura dos relatórios de estágio revela que algumas atividades ou procedimentos didáticos são realizados em decorrência do contexto situacional imediato, vivenciado em sala de aula. Os saberes docentes não são necessariamente excludentes, mas se embaralham nas interações profissionais, assim como as práticas de letramento grafocêntricas e digitais. 


\section{Letramentos na formação do professor}

O enfoque desta pesquisa recai sobre o letramento do professor em formação inicial. O letramento digital corresponde a usos de ferramentas digitais ou hipermodais, mediados pela escrita, para propósitos específicos. No contexto de instrução formal tematizado nesta investigação, as práticas de letramento digital requerem dos alunos-mestre a competência para manusear a tecnologia e a apropriação crítica dos usos mencionados, no complexo contexto de formação inicial e, inclusive, no futuro local de trabalho. A partir do empoderamento dos alunos-mestre, espera-se a construção de significativas situações de aprendizagem mediadas pelas ferramentas mencionadas, também em função do fortalecimento dos alunos da escola básica, em resposta às demandas de práticas de letramento instauradas no cotidiano. O letramento digital está além da simples possibilidade de consumo. Trata-se da efetiva apropriação de chaves para a ação social. Pressupõe a formação de agentes sociais, atores ou cidadãos autônomos. Nessa perspectiva, as tecnologias moldam e, ao mesmo tempo, são moldadas pelas infindáveis práticas sociais.

A investigação sobre a apropriação das TIC na formação dos alunosmestre pode contribuir para o fortalecimento do trabalho pedagógico a ser realizado por eles, no espaço de atuação profissional: escolas de ensino básico. Em função dos usos dessas tecnologias nos estágios supervisionados, realizamos uma releitura das noções teóricas de "letramento do professor" e de "agente de letramento", propostas por Kleiman (2006, 2008, 2009), no âmbito dos estudos brasileiros do letramento, desenvolvidos no campo da Linguística Aplicada. A partir da intervenção realizada, as práticas de letramento convencional, informadas pela cultura grafocêntrica, embaralham-se, com maior visibilidade, a práticas de letramento digital, podendo resultar em inovações para o contexto focalizado de formação inicial do professor.

Nessa perspectiva, o letramento do professor não se configura "como mero instrumento para realização do trabalho, mas como aspecto constitutivo, identitário de sua função como formador de novos leitores e 
usuários da língua escrita, ou seja, intrinsecamente ligado a sua atuação profissional" (KLEIMAN, 2009, p. 21). Por "agente de letramento", compreendemos "um agente social com capacidade para articular os interesses partilhados, organizar o grupo para a ação conjunta, gerar movimentos sociais e exercitar influência, como coletividade, no processo de tomar decisões" (KLEIMAN, 2008, p. 415).

Nesta pesquisa, o ensino básico está diretamente vinculado à formação inicial do professor nas licenciaturas. As instituições de ensino precisam considerar os efeitos das tecnologias sobre as práticas escolares de linguagem (leitura, escrita e análise linguística), as quais organizam as aulas de Língua Portuguesa. Com enfoque voltado para o ensino básico, pesquisas sobre letramento digital apontam diversos desafios e perspectivas para o magistério, quando se tenta incorporar as TIC como instrumento de mediação para as diversas práticas sociais de escrita e, consequentemente, para a aprendizagem em sentido amplo (COSCARELLI, 2003; BUZATO, 2007; BRAGA; MORAES, 2009; BRAGA, 2010)7.

Os multiletramentos são necessários e exigidos nos contextos interativos da vida diária. São compreendidos como "[...] multiplicidade cultural das populações e a multiplicidade semiótica de constituição dos textos por meio dos quais ela se informa e se comunica" (ROJO, 2012, p. 13). Esses letramentos não podem ser ignorados nos espaços institucionalizados de instrução. À escola, soma-se o desafio de desenvolver a habilidade dos alunos de ler e de produzir textos hipermodais, além de outras habilidades, uma vez que esses textos imprimem diferentes formas de conceber a leitura e escrita. Às licenciaturas, cabe qualificar os acadêmicos para se apropriarem de práticas de letramento digital em função das demandas para o futuro local de trabalho, de modo que as TIC não se configurem como uma

\footnotetext{
7 "a instituição escolar se encontra cada vez mais diante da necessidade de repensar sua funcionalidade, reavaliar suas estratégias e (re)inventar suas práticas, com o fito de tentar responder às exigências multifacetadas dessa nova era digital, que se reorganiza de forma cada vez mais dinâmica e redefine novos papéis institucionais cada vez mais interrelacionados com os usos das TIC que emergem no cenário atual do mundo globalizado" (PINHEIRO, 2012, p. 248).
} 
surpresa no contexto da sala de aula do ensino básico. Sobre as demandas instauradas pelas TIC para as licenciaturas, Signorini (2012) esclarece que:

fica mais evidente a necessidade de uma inserção mais efetiva e esclarecida dos formadores e formandos em Letras nos debates sobre os novos letramentos que invadiram o cotidiano, mas que ainda não são efetivamente objetos de ensino. [...] tal inserção poderá contribuir para uma melhor qualificação dos futuros profissionais que enfrentarão (ou já estão enfrentando) o desafio de levar seus alunos a se apropriarem desses letramentos enquanto cidadãos - ou seja, enquanto indivíduos e grupos capazes de fazer ligações mais proficuas entre linguagem, saber e poder -, e não apenas enquanto consumidores de produtos tecnológicos (SIGNORINI, 2012, p. 282-283).

Visando a inserção dos alunos-mestre em práticas docentes que efetivamente utilizam de forma critica as tecnologias, foram abordadas algumas estratégias pedagógicas no momento da intervenção que eram subsidiadas por artefatos tecnológicos. Tais artefatos, compreendidos como "qualquer objeto produzido por TIC" (SIGNORINI; CAVALCANTI, 2010, p 422), foram problematizados como recursos didáticos ${ }^{8}$. Nesse sentido, interessamo-nos em criar estratégias de uso de ferramentas digitais produtivas para o ensino de língua materna.

Recorrendo ao uso de computadores, acesso à internet, projetores de texto, dentre outros artefatos, objetivamos criar situações de uso de TIC que favorecessem tanto à formação dos alunos-mestre quanto ao planejamento e à prática pedagógica dos futuros professores. As atividades práticas e leituras teóricas desenvolvidas visaram a problematizar os usos das ferramentas digitais, apontando para o uso de plataforma e gêneros digitais que favorecessem diferentes práticas, inclusive as pedagógicas. As TIC, na intervenção realizada, foram mobilizadas para atender a fins específicos, como recursos didáticos que podem otimizar o ensino de língua materna.

\footnotetext{
${ }^{8}$ As autoras compreendem "artefato digital como qualquer objeto produzido por TIC, ou seja, tanto sistemas e programas computacionais (software) e suas 'interfaces de usuário', quanto os objetos físicos que os abrigam (computadores, mas também os vários objetos móveis e fixos produzidos pelas chamadas computação ubíqua, pervasiva e embarcada" (SIGNORINI; CAVALCANTI, 2010, p. 422).
} 
Os alunos-mestre que se esforçam para mobilizar práticas de letramento digital, em aulas do ensino básico, depararam-se com tensões ou conflitos diferenciados no trabalho pedagógico. A inovação do ensino não depende apenas do professor, mas, dentre outros atores, da estrutura organizacional escolar, no sentido de dar condições para a realização de práticas inovadoras. De acordo com os relatórios analisados, as escolas de ensino básico possuem diversos artefatos tecnológicos, porém os usuários contam com desafios na logística: há Internet wi-fi disponivel na escola, mas apenas os aparelhos dos professores podem conectá-la, já que os alunos não têm acesso, por exemplo. Com barreiras desse tipo, uma proposta pedagógica que envolva navegação na Internet pode ser comprometida. O próprio espaço escolar limita práticas inovadoras a partir do uso da tecnologia digital.

A escola não pode ignorar os novos estatutos da escrita e da leitura, as novas formas de conceber os textos. Tanto no âmbito do ensino básico quanto na formação inicial de professores, há a necessidade de preparar atores sociais para participar de diferentes práticas de letramento, informadas pela tecnologia digital. Investigando o letramento digital na esfera de formação docente, Buzato (2006) enfatiza a necessidade de oferecer formação inicial ou continuada aos professores, objetivando a capacitação de profissionais capazes de integrar os artefatos digitais como instrumentos de mediação da aprendizagem. Tais profissionais também precisam lidar com a leitura e a escrita em plataformas digitais, haja em vista que o ciberespaço compreende diferentes práticas de letramento na contemporaneidade.

\section{Resultados produzidos}

A análise comparativa dos relatórios produzidos ao longo de três estágios supervisionados revelou a construção de saberes sobre letramento digital no ensino de Língua Portuguesa. Neste momento inicial, também consideramos dois ensaios acadêmicos produzidos pela dupla focalizada, durante a intervenção realizada na terceira disciplina de estágio. O terceiro relatório e os ensaios foram atividades escritas solicitadas aos alunos-mestre 
na intervenção. A partir de três textos apresentados como referência ${ }^{9}$, foi solicitada aos alunos-mestre alguma articulação entre práticas escolares de leitura e escrita, envolvendo o fenômeno da retextualização e o uso do hipertexto no ensino de lingua materna.

No Quadro 1, reproduzimos passagens dos textos em que a dupla procura articular o ensino de lingua materna ao uso de TIC como recurso pedagógico.

\section{Quadro 1 - Construção de Saberes}

\begin{tabular}{|c|c|}
\hline & $\begin{array}{l}\text { A partir da discussão desse texto, uma aluna lembrou de um outro que } \\
\text { a turma já havia lido: A menina que falava internetês, de Rosana } \\
\text { Hermann [...] A professora então procurou o texto no LD, leu novamente } \\
\text { com a turma que participou efetivamente da leitura, pois se tratava de } \\
\text { um assunto presente em suas vidas: o uso da internet. (Relato reflexivo } \\
\text { das aulas observadas) }\end{array}$ \\
\hline $\begin{array}{l}\text { Relatório } \\
\text { II/2011.2 }\end{array}$ & $\begin{array}{l}\text { Com a proposta da utilização da internet e da criação do blog, propomo- } \\
\text { nos a trabalhar um tema que fosse da realidade dos alunos, pois é } \\
\text { notável o interesse dos alunos por esse tipo de abordagem. (Análise das } \\
\text { aulas ministradas) }\end{array}$ \\
\hline & $\begin{array}{l}\text { Por meio da utilização do blog nas aulas, tentamos trazer algo que os } \\
\text { alunos tenham familiaridade e, assim, mudar (pelo menos em nossas } \\
\text { aulas) a concepção de que, como afirma Coscarelli 'À escola cabe } \\
\text { didatizar e limitar os percursos dos alunos no computador a } \\
\text { determinados sites informativos (ensinar a usar). Em casa, por outro } \\
\text { lado, as crianças podem conversar no MSN, participar de Orkut, } \\
\text { explorar o Youtube, fazer e visitar blogs, jogar, etc. (usar, explorar o } \\
\text { computador). (COSCARELLI } 2009 \text {, p. 558)' } \\
\text { Ou seja, tentamos fazer na sala de aula o que os alunos fazem em casa } \\
\text { para que eles pudessem compreender as várias finalidades dessas } \\
\text { ferramentas. (Análise das aulas ministradas) }\end{array}$ \\
\hline & $\begin{array}{l}\text { Ai aparece um desafio para os docentes: criar situações em sala de aul } \\
\text { que permitam aos alunos a apropriação da diversidade dos gêneros } \\
\text { diversidade essa que já faz parte da vida deles. Uma boa saida é } \\
\text { utilização da internet nas aulas de lingua materna. } \\
\text { [O hipertexto] Pode ser também uma ótima maneira para o professo } \\
\text { usar no incentivo para o aluno na prática da leitura em sala de aula. }\end{array}$ \\
\hline
\end{tabular}

\footnotetext{
${ }^{9}$ Eis os textos: DELL'ISOLA R. L. P. Retextualização de Gêneros Escritos. Rio de Janeiro: Lucerna, 2007; GOMES, L. F. Hipertexto no Cotidiano Escolar. São Paulo: Cortez, 2011; KOCH, I. V.; ELIAS, V. M. Ler e Escrever - estratégias de produção textual. 2. ed. São Paulo: Contexto, 2011. A proposta do ensaio objetivava o aprofundamento pelos alunos das discussões desenvolvidas em sala de aula sobre práticas de letramento digital no ensino de lingua materna.
} 
Em todas as passagens reproduzidas no Quadro 1 há um consenso sobre o uso de TIC como instrumento de mediação da aprendizagem, contribuindo para inovação do ensino de língua materna, o que é perceptível pelo uso de formas linguísticas com juízo de valor positivo: efetivamente; notável o interesse; uma boa saida; uma ótima maneira; incentivo; o interesse. Nos dados, é perceptível o encantamento dos alunos-mestre por artefatos digitais no ensino de lingua materna, como se apenas a presença da tecnologia garantisse a maior produtividade do ensino.

No Relatório I, a dupla observa maior interesse por parte dos alunos quando o assunto da leitura envolve o conteúdo da Internet, o que seria justificável, segundo a própria dupla, pela familiaridade do assunto pelos discentes. No Relatório II, a partir da primeira regência, é defendido o uso de ferramentas digitais como uma forma de aproximar os discentes dos conteúdos disciplinares a serem trabalhados em aula. Nos primeiros estágios, observamos uma manutenção do argumento em defesa do uso da Internet nas aulas. No entanto, no primeiro estágio, a Internet surge a partir de uma sugestão de um aluno, ao passo que, no segundo estágio, a iniciativa do trabalho surge dos alunos-mestre, a partir da constatação do interesse dos discentes em aula.

No Relatório III, alguns usos da Internet são apresentados como familiares aos alunos, restando à escola oferecer novas possibilidades de interação entre os alunos e o computador, contribuindo para o comprometimento dos alunos com os estudos e, consequentemente, para o aprendizado discente. Nos ensaios, a perspectiva argumentativa sofre alteração, quando comparada à dos relatórios: o aluno deixa de ser alvo direto da questão tematizada e o ensino de Lingua Portuguesa passa a demandar práticas produtivas para o aprendizado discente. Essa mudança de perspectiva também é justificada pelo gênero textual selecionado para a atividade proposta: o relatório de estágio demanda reflexões mais espontâneas sobre a prática pedagógica, enquanto o ensaio acadêmico, 
ainda que tematizasse o ensino de lingua materna, objetiva principalmente a articulação ou confronto de teorias em função da prática pedagógica.

\subsection{Relatório I - Reflexões sobre observação de aulas}

O relatório de observação corresponde ao registro da experiência vivenciada pelos alunos-mestre, ao se dirigirem à escola campo de estágio para observar aulas da disciplina Lingua Portuguesa. Tal observação é orientada pela literatura acadêmica de referência, estudada nas aulas de estágio supervisionado, ministradas na universidade. No relatório, são descritas e analisadas práticas pedagógicas informadas exclusivamente pela tradição da cultura escolar grafocêntrica: Referente à leitura, a professora utilizava o livro didático como suporte, todas as leituras feitas em sala de aula foram únicas e exclusivamente do livro didático (Relatório I, 2011.1 - Relato reflexivo das aulas observadas). No trecho transcrito, as formas linguísticas de função adverbial únicas e exclusivamente evidenciam o domínio exercido pelo livro didático na aula observada.

Dada a ação exercida pelo livro didático em sala de aula, o espaço para a criatividade não escapava ao uso desse material: A partir da leitura e discussão desse texto, seguindo as orientações do LD, a professora solicitou que os alunos produzissem um texto sobre um fato da vida e trouxessem na próxima aula (Relatório I, 2011.1 - Relato reflexivo das aulas observadas). Apesar da limitação das aulas observadas, é relatado um momento de ruptura na sequência de atividades didáticas sugeridas no livro didático, conforme podemos observar no Exemplo 1.

\section{Exemplo 1}

Após a leitura, a professora iniciou uma discussão sobre as diversas formas de linguagem, mostrando como o poeta brinca com as palavras no poema de Paulo Leminski [...]. A partir da discussão desse texto, uma aluna lembrou de outro que a turma já havia lido: A Menina Que Falava Internetês, de Rosana Hermann [...]. A professora então procurou o texto no $\mathrm{LD}$, leu novamente com a turma que participou efetivamente da leitura, pois se tratava de um assunto presente em suas vidas: uso da internet. Eles deram exemplos de palavras que usavam em conversas nas páginas de relacionamento como Orkut e MSN. / Apesar da produção de texto ser realizada 
apenas uma vez durante o período que estivemos observando as aulas da professora, notamos a participação efetiva da turma, tornando, a nosso ver, a aula mais produtiva. (Relatório de estágio I, 2011.1 - Relato reflexivo das aulas observadas).

No Exemplo 1, é descrito um momento de descontinuidade em relação às sequências de atividades nas aulas observadas. Como o assunto discutido estava relacionado às diversas formas de uso da língua, os discentes, familiarizados com variadas formas de escrita em ambientes virtuais, envolveram-se bastante na discussão sobre o assunto, relatando algumas experiências vivenciadas. As experiências de letramento dos atores sociais precisam ser visibilizadas no espaço escolar. No sentido de valorizar os saberes discentes, a dupla entendeu tal prática como uma forma mais produtiva para o trabalho com a leitura e a escrita no ensino básico. Conforme mostraremos adiante, os alunos-mestre parecem se apropriar dessa experiência para as atividades de regência de aulas nas disciplinas subsequentes de estágio supervisionado.

\subsection{Relatório II - Reflexões sobre regência de aulas}

No segundo relatório, momento em que são observadas e regidas aulas no ensino básico, os alunos-mestre parecem retomar a experiência vivenciada no estágio de observação, pois privilegiaram artefatos digitais como recursos didáticos. Como o acesso e o uso da Internet, no cotidiano dos alunos, eram do conhecimento da dupla, entendeu que o trabalho com o recurso digital seria produtivo nas aulas ministradas, podendo resultar na inovação do ensino de Língua Portuguesa.

Exemplo 2

Quando questionamos sobre o acesso a computador e a Internet nos surpreendemos: $100 \%$ (cem por cento) da classe já estava inserida a esse mundo. Isso de alguma forma facilitou nosso trabalho nessa aula, pois pudemos contar com a ajuda efetiva dos alunos no momento de construção do blog (criação da conta e layout da página: imagens referentes aos temas postados no blog, cores das fontes e o tema da página). (Relatório de estágio II, 2011.2, Análise das aulas ministradas). 
O Exemplo 2 mostra que, contando com os saberes experienciais, a dupla envolveu os alunos na produção de textos em plataforma digital, além de envolvê-los na criação da própria plataforma por meio de blog, o que não demandou grandes esforços, pois os discentes estavam familiarizados com diferentes linguagens. Ao exercerem a função de professores, os alunosmestre propiciaram a aprendizagem colaborativa, a qual deve ser apropriada e utilizada pelos alunos nas esferas da vida diária.

Mesmo justificando o uso de ferramentas digitais devido à familiaridade dos alunos com o ciberespaço, a dupla parece se deparar com um dado inesperado durante o estágio. Esse dado é sinalizado pela forma verbal surpreendemos: os alunos-mestre não contavam com 100\% de adesão à Internet pelos alunos do ensino básico. Apesar dessa realidade descrita, lembramos que, no contexto tocantinense focalizado, ainda há escolas com recursos didáticos limitados, bem como alunos que se envolvem em práticas de leitura significativas apenas no espaço escolar. A precariedade na educação não está restrita a práticas de letramento digital. Como defende Selber (2004), as TIC estão sendo agregadas aos muitos desafios a serem enfrentados pela educação, como o letramento convencional ou, até mesmo, a alfabetização.

Além do saber experiencial, os alunos-mestre justificam suas práticas pedagógicas ancorando-se em saberes disciplinares, na tentativa de irem além das práticas de letramento escolar, características da tradição do ensino. No trecho reproduzido no Exemplo 3, a dupla justifica o uso do computador aliado à produção textual, lançando mão de referenciais teóricos sobre o letramento digital. A dupla traz um argumento de autoridade para fundamentar as práticas pedagógicas.

Exemplo 3

Estando entre as alternativas disponiveis para muitas comunidades de cultura escrita, o computador ampliou as possibilidades de atuação por meio de textos. É entendido como ambiente de leitura e escrita. Insistimos nessa perspectiva de trabalho, pois concordamos com Ribeiro (2002) 
[...]. Soares (2003) inclui as ferramentas digitais entre as habilidades necessárias para o desenvolvimento do grau de letramento surgindo assim mais uma subcategoria do letramento, o letramento digital. (Relatório de estágio II, 2011.2, Análise das aulas ministradas).

\subsection{Relatório III - Reflexões sobre regência de aulas}

No terceiro relatório, a fundamentação teórica sobre letramento digital é utilizada ao longo do relato das atividades experienciadas na escola de ensino básico. Em resposta à intervenção pedagógica, o objetivo das aulas ministradas é bastante claro: trabalhar o letramento digital no ensino de lingua materna. No relatório do segundo estágio, a literatura sobre letramento digital foi utilizada como referência para uma atividade pontual, ao passo que, no terceiro estágio, é assumida como saber acadêmico orientador da prática profissional, conforme observamos no Exemplo 4.

\footnotetext{
Exemplo 4

Para este semestre, a proposta da oficina foi trabalhar o letramento digital. Para tanto, o professor nos orientou durante as aulas na universidade com o auxílio de texto sobre o referido assunto. Por ser um tema atual nos estudos sobre ensino de língua materna, tivemos como base teórica BRAGA \& MORAES (2009) e COSCARELLI (2009) (Relatório de estágio III, 2012.1, Análise das aulas ministradas).
}

No Exemplo 4, o conteúdo disciplinar das aulas ministradas pela dupla é apresentado articuladamente a saberes acadêmicos trabalhados na universidade. Duas referências bibliográficas estudadas nas aulas teóricas do estágio são citadas no relatório, evidenciando a interferência direta dos saberes acadêmicos sobre as atividades práticas, bem como a relevância da pesquisa em Linguística Aplicada para a formação inicial de professores.

Em outro momento do relatório, a dupla procura justificar a escolha do trabalho escolar mediado pela tecnologia digital. Recorre ao digital para atender demandas específicas do ensino de Língua Portuguesa, como o desenvolvimento das habilidades de leitura e escrita dos alunos, com textos hipermodais: "Nessa perspectiva, nos propomos a incluir nossos alunos no contexto digital. Pelo fato de eles já estarem inseridos nesse mundo, 
pretendemos direcionar o uso das Tecnologias de Informação e Comunicação (TIC) para o ensino de língua portuguesa" (Relatório de estágio III, 2012.1).

Conforme evidenciamos nos documentos focalizados, no relatório I, é apresentado um descontentamento com a prática pedagógica observada no ensino básico, quando apenas o livro didático orientava as aulas de Língua Portuguesa. Durante a regência de aulas dos alunos-mestre, no relatório II, a tecnologia digital é incorporada ao planejamento como uma tentativa de tornar a aula mais atrativa. No relatório III, momento em que foi realizada a intervenção pedagógica, a dupla detém-se à análise dos recursos tecnológicos mobilizados durante o periodo de regência, evidenciando o papel social da tecnologia digital na vida diária, transcendendo a fronteira da concepção dessa tecnologia apenas como aparato desencadeador da motivação em sala de aula.

\section{Considerações finais}

A pesquisa desenvolvida sobre a construção de práticas de letramento digital, nos estágios supervisionados obrigatórios, revela demanda por inovação na formação inicial de professores nas licenciaturas, o que é motivado pelo diálogo mais estreito entre a universidade e as escolas de ensino básico, desencadeado nas referidas disciplinas. A inserção da tecnologia digital, associada aos conteúdos específicos do curso, no currículo das licenciaturas, corresponde apenas a uma demanda tematizada diretamente neste artigo.

A inserção da tecnologia digital no currículo precisa ser realizada criticamente, sem concebê-la com o encantamento demonstrado pelos alunos-mestre nos dados aqui analisados, pois a simples presença de aparatos tecnológicos em sala de aula não garante o ensino produtivo de Língua Portuguesa. Apesar de produtivas, apenas as discussões sobre tecnologia, realizadas em sala de aula, também não garantem a inserção dos aprendizes em efetivas práticas de letramento digital, seja no contexto de instrução formal da universidade ou das escolas de ensino básico. Nas 
licenciaturas, os estágios supervisionados precisam se configurar como laboratórios da prática pedagógica.

Destacamos a importância dos estágios supervisionados obrigatórios para a inovação do ensino nas licenciaturas brasileiras, o que é justificável pelo contato estabelecido diretamente entre a universidade e as escolas de ensino básico. A inovação se constrói pela conjugação de diferentes atores sociais integrantes do espaço social complexo das disciplinas. Tal conjugação se instaura pelo estreito diálogo entre disciplinas do conhecimento, as quais possibilitam aos professores, alunos-mestre, formadores e pesquisadores lidarem com os atores mencionados.

\section{Referências}

BRAGA, D. B. A comunicação interativa em ambiente hipermídia: as vantagens da hipermodalidade para o aprendizado no meio digital. In: MARCUSCHI, L. A.; XAVIER, A. C. (Org.). Hipertexto e gêneros digitais: novas formas de construção de sentidos. 3. ed. São Paulo: Editora Cortez, 2010. p. 144-162.

BRAGA, D. B.; MORAES, A. M. Pesquisa na web e produção textual: reflexões sobre o ensino do gênero dissertativo na escola. Linguagem em (Dis)curso, v. 9, n. 3, p. 603-620, 2009.

BUZATO, M. K. Entre a fronteira e a periferia: linguagem e letramento na inclusão digital. $285 \mathrm{f}$. Tese (Doutorado em Linguística Aplicada) Universidade Estadual de Campinas, Campinas, SP, 2007. . Letramentos Digitais e Formação de Professores. In: III CONGRESSO IBERO-AMERICANO EDUCAREDE, 2006, São Paulo. Anais... São Paulo: CENPEC, 2006. p. s/p. COSCARELLI, C. V. Espaços hipertextuais. In: II ENCONTRO INTERNACIONAL LINGUAGEM, CULTURA E COGNIÇÃO. Belo Horizonte. Anais... Belo Horizonte: Faculdade de Educação, 2003.

GIBSON, S. Narrative of a Pre-Service Teacher. English Teaching: Practice and Critique. New Zealand: The University of Waikato, v. 2, n. 3, p. 35-46, 2003.

KLEIMAN, A. B. Projetos dentro de projetos: ensino-aprendizagem da escrita na formação de professores de nível universitário e de outros agentes de letramento. Scripta, v. 13, n. 24, p. 17-30, 2009.

KLEIMAN, A. B. Os estudos de letramento e a formação do professor de língua materna. Linguagem em (Dis)curso, v. 8, n. 3, p. 519-541, 2008.

. Professores e agentes de letramento: identidade e posicionamento social. Revista Filologia e Linguística Portuguesa, v. s/v, n. 8, p. 409-424, 2006. 
MELO, L. C. de. Formas linguisticas do outro e de si-mesmo na escrita reflexiva acadêmico-profissional de Relatórios de Estágio de professores de linguas. 2015. 170 f. Tese de Doutorado em Letras: Ensino de Língua e Literatura, Universidade Federal do Tocantins, Araguaína, 2015. PINHEIRO, P. A. Práticas colaborativas de escrita por meio de ferramentas da internet: ressignificando a produção textual no contexto escolar. In: SIGNORINI, I.; FIAD, R. S. (Org.). Ensino de lingua: das reformas, das inquietações e dos desafios. Belo Horizonte: Editora UFMG, 2012. p 248281.

RIBEIRO, A. E.; COSCARELLI, C. V. O que dizem as matrizes de habilidades sobre a leitura em ambientes digitais. Educação em Revista, v. 26, n. 3, p. 317-334, 2010.

ROJO, R. Letramentos múltiplos, escola e inclusão social. São Paulo: Parábola Editorial, 2009.

SELBER, S. T. Multiliteracies for a Digital Age. Carbondale, IL: Southern Illinois UP, 2004.

SIGNORINI, I. Letramentos multi/hipermidiáticos e formação de professores de língua. In: SIGNORINI, I.; FIAD, R. S. (Org.). Ensino de lingua: das reformas, das inquietações e dos desafios. Belo Horizonte: Editora UFMG, p. 282-303, 2012.

Significados da inovação no ensino de lingua portuguesa e na formação de professores. Campinas (SP): Mercado de Letras, 2007. SIGNORINI, I.; CAVALCANTI, M. do C. Lingua, linguagem e mediação tecnológica. Trabalhos em Linguística Aplicada, v. 49, n. 2, p. 419-440, 2010. SILVA, W. R. Escrita do gênero relatório de estágio supervisionado na formação inicial do professor brasileiro. Revista brasileira de linguística aplicada, v. 13, n. 1, p. 171-195, 2013.

Estudos do letramento do professor e formação inicial nos estágios supervisionados das licenciaturas. In: SILVA, W. R. (Org.). Letramento do professor em formação inicial: interdisciplinaridade no estágio supervisionado da licenciatura. Campinas: Pontes Editores, 2012b. p. 27-49.

Construção da interdisciplinaridade no espaço complexo de ensino e pesquisa. Cadernos de Pesquisa, v. 41, n.143, p. 582-605, 2011.

SILVA, W. R.; BRITO, C. C. de P.; MARTINS, R. G.; SANTOS, S. A. Como formadores e alunos da Licenciatura em Letras compreendem a Linguística Aplicada? Revista Brasileira de Linguistica Aplicada, v. 17, n. 1, p. 31-60, 2017.

SILVA, W. R.; DINIZ, A. L. S. Estágio supervisionado obrigatório das licenciaturas como contexto de pesquisa da linguística aplicada. Trabalhos em Linguística Aplicada, v. 53, n. 2, p. 333-355, 2014. 